\title{
Psychosocial Health and Workability among Staff Working with People with Cognitive Restrictions and Intellectual Disabilities
}

\author{
Cathrine Oscarsson Kjellstrand, Gunvor Gard* \\ Department of Health Sciences, Lund University, Lund, Sweden \\ Email: Cathrinekjellstrand@telia.com, ${ }^{*}$ Gunvor.Gard@med.lu.se
}

Received 10 August 2014; revised 26 September 2014; accepted 9 October 2014

Copyright (C) 2014 by authors and Scientific Research Publishing Inc.

This work is licensed under the Creative Commons Attribution International License (CC BY). http://creativecommons.org/licenses/by/4.0/

(c) (i) Open Access

\begin{abstract}
Little is known about the psychosocial work situation among staff working with people with cognitive restrictions, and research is needed. Aim: The aim of this study was to describe the symptom panorama and psychosocial work situation of staff working with people with cognitive restrictions and to identify predictors for their job satisfaction and workability. A cross sectional study was performed. Method: The Questionnaire Psycho Social Nordic (QPS-Nordic questionnaire) was used. Results: The results showed that the majority of the staff working with people with cognitive restrictions were satisfied with their job, but musculoskeletal symptoms were described by $40 \%$. Decision demands at work were high compared to quantitative and learning demands. Musculoskeletal symptoms were related to low ability to master the work, low job control and high job demands. Symptoms from the neck region were correlated to stress. A low level of neck pain was related to a high level of job satisfaction. Predictors for workability were positive challenges in work and not being hindered by musculoskeletal symptoms in work. Predictors for job satisfaction were mastery, workability and not having pain during the last 7 days. Conclusion: Due to the relatively small sample the results should be interpreted with caution. The results indicated that positive challenges in work and not being hindered by musculoskeletal disorders predicted workability in this group and that mastery, workability and not having pain during the last 7 days predicted job satisfaction.
\end{abstract}

\section{Keywords}

Musculoskeletal Disorders, Workability, Job Demands, Job Satisfaction

\footnotetext{
${ }^{*}$ Corresponding author.
}

How to cite this paper: Kjellstrand, C.O. and Gard, G. (2014) Psychosocial Health and Workability among Staff Working with People with Cognitive Restrictions and Intellectual Disabilities. Health, 6, 2481-2489. 


\section{Introduction}

Health promotion can be defined as the process of enabling people to increase control over, and to improve, their health. It is a process directed towards enabling people to take action, and thereby improve health [1]. In a workplace context, health can be seen as a dynamic balance between personal resources and workplace factors [2]. Similarly, workability can be seen as a balance between a person's resources and the demands of work [3], where the former is linked to health and functional abilities, values, attitudes, education, work skills and health practices and the later to the actual content, demands and organization of work [3] [4].

Work involving high physical and ergonomically demands, such as home care and social service work, requires high physical and psychosocial workability from the staff [5]. Healthcare professionals are exposed to a lot of different stressors which can affect physical and mental health and also decrease work engagement. The most significant predictors for work engagement among health care workers have been shown to be workload, mental health and job satisfaction. To increase work engagement, interventions should focus on workload, worker's personal expectations and job satisfaction [6].

In Sweden, women represent $86 \%$ of all employees working in caring and social services and are also those who report more symptoms due to mental strain at work than other professionals [7]. Of all employed persons in Sweden 2010, 23\% of the women and $17 \%$ of the men suffered from different pain conditions related to work [7]. Work-related factors such as heavy lifting, repetitive work, low autonomy, stress, and lack of influence at the workplace are factors that contribute to the risk of developing musculoskeletal disorders (MSDs) [7]-[9].

Most MSDs develop as a result of repeated or long-lasting exposure to high workload and are influenced either by the work itself or by factors in the employees' working environment [10]. Psychosocial variables such as high psychological demands, low social support, and low management support have been shown to predict musculoskeletal pain [11]-[13]. Factors such as regular physical exercise and positive support are important for health at work and may increase job satisfaction and reduce the incidence of musculoskeletal disorders [11] [14]-[16].

In recent decades there have been major improvements of the physical work environment, such as regulation of working hours and the opportunity to take rests and pauses at work. However, musculoskeletal disorders are still in combination with psychosomatic disorders common causes of work-related diseases in Sweden [9] [17].

Professionals, working with people with cognitive restrictions, have an important job not only as caregivers, but also as role models for the care recipients and they may have an important impact on the health of the care recipients [18]. It is also a psychosocially demanding job with high psychosocial and emotional workload, which can influence wellbeing and quality of life and influence their level of caring for the patients. It is important to promote health and well-being for this professional group [19] [20]. Earlier knowledge about this professional group is scarce, but earlier research results show that the staff perceive high stress and need more support and opportunities to interact with supervisors to improve their work situation [18] [20] [21]. It is important to increase the knowledge of how professionals working with people with cognitive restrictions perceive their psychosocial working environment in terms of job demands, job control, decision control and challenges at work.

To identify and address potential health risks is of great importance to prevent illness among health professionals, as stress and stress-related disorders can reduce quality of care [19] [20]. To coach employees in dealing with difficult situations at work and to teach them to be more aware of their body signals of stress can be important interventions to maintain and increase health among health professionals [20]. There is a need for further studies and increased evidence for psychosocial interventions in this area. Today there is a lack of knowledge about the psychosocial work situation of professionals working with people with cognitive restrictions as a basis for health promoting interventions [19]. In addition, knowledge about predictors for their job satisfaction and workability is needed.

\section{Aim}

The aim of this study was to describe the musculoskeletal symptom panorama, the psychosocial work situation and predictors for workability and job satisfaction among staff working with people with cognitive restrictions.

\section{Research Questions}

1) How was the frequency of musculoskeletal symptoms and physical exertion at work?

2) How was the psychosocial work situation perceived? 
3) Which predictors could explain a good workability and job satisfaction?

\section{Methods}

\subsection{Subjects}

All care aides and nursing assistants, 190 professionals, working in 19 different group homes with people with intellectual disabilities and cognitive restrictions in a community in the south of Sweden was asked to participate in a questionnaire study. In total 65 people responded to the survey (34\%), 55 women and 8 men. The distribution of women and men was the same as for the whole group of care aides and nursing assistants at the workplace, $87 \%$ was female and $13 \%$ men. The all had education as care aide or nursing assistant and had worked in their profession between 2 to 10 years. Since there were only eight men participating in the study we found no reason to analyze them separately. Two respondents did not state their gender. The average age of the respondents were 45 years, 8 people have not specified age. Of the respondents 43 persons worked full time and 20 worked part-time. Two did not answer this question.

\subsection{Evaluation Scales}

A cross sectional study was performed. Dimensions from the Questionnaire Psycho Social Nordic (QPS-Nordic) questionnaire, a reliable and valid psychosocial questionnaire, were used to study the psychosocial work situation [22] [23]. Each item in the QPS questionnaire is developed as a five-point scale were 1 stands for "very seldom or never" and 5 for "very often or always" [22]-[24]. Psychosocial indexes were developed from the questions within each are a according to the QPS guidelines [24]. The areas were mastery (6 questions), job demands (10 questions), quantitative work demands (QWD) (4 questions), learning demands (LD) (3 questions), decision demands (3 questions), job control (12 questions), positive challenges at work (PC) (3 questions), decision control (DC) (5 questions) and work pace control (WPC) (4 questions) [22] [23]. The mean value of the questions within each area was used to develop each index according to the QPS guidelines [24]. The QPS Nordic questionnaire has been tested for reliability and validity among workers in administrative and service work with satisfactory reliability and validity [24].

The "standardised Nordic questionnaire for the analysis of musculoskletal symptoms" was used to collect data concerning musculosceletal symptoms from different body regions [25]. Job satisfaction was measured with the question “are you satisfied with your current job” from QPS Nordic [23]. Workability index consists of four questions including a question about perceived stress [26] [27]. Perceived exertion was rated according to Borg [28] varying from 6 to 20. Pain was rated by VAS according to the Nordic Council of Ministers varying from 0 to 10 [29]. The Ethical Committee at the Department of Health Sciences at Lund University has approved the study.

\subsection{Statistical Methods}

A multiple regression analysis (linear regression method stepwise analysis) were performed with the work-ability index and job satisfaction respectively as dependent variables and with individual background variables such as age and sex and all psychosocial indexes as independent variables [30]. In addition, when job satisfaction was the dependent variable, workability was also included in the analysis as it also may influence job satisfaction and when workability was the dependent variable job satisfaction was also included in the analyses as it also may influence workability.

\subsection{Procedure}

Written information about the study was sent to the managers at each workplace and distributed to the employees. They all received information about the study and confidentiality and those interested gave their informed consent. The questionnaires were collected by the author. Reminders were given twice by email. In total, 190 questionnaires were sent out and 65 returned, $34 \%$ of the total.

\section{Results}

\subsection{How Was the Prevalence of Musculoskeletal Symptoms and Physical Exertion?}

Complaints from all body parts were present, but neck, lumbar and wrist symptoms and were the most frequent- 
ly mentioned, indicated by $40 \%$ of the group. The symptoms from these three body regions were used in the following analyses. Physical exertion was measured with Borg's Perceived Exertion $(n=60)$ [28] and had a mean of 12 (sd 2, 8).

\subsection{How Was the Psychosocial Work Situation Perceived?}

In total, $80 \%$ of the respondents perceived that they were satisfied with their current job. The mean value of the index mastery of the work situation was 3.7, indicating a good ability to master various problems at work. However, the mean values varied on individual questions from 2.8 to 4.0. The mastery question that had a mean value of 4.0 was "Are you content with your ability to maintain a good relationship with your coworkers at work" and the question with the lowest mean value of 2.0 was "Do you get information about the quality of the work you do"?

Job demands were studied both as indexes; quantitative job demands, learning demands and decision demands and as individual questions within these indexes (Table 1). The decision demands were high compared to the quantitative job demands and the learning demands. The individual question "Does your work require maximum attention had the highest mean value, 4.0, showing that the respondents "very often" felt that work required maximum attention. The question "Does your work require complex decisions" had the lowest mean of 3.1 were 3 at the five-point scale stands for "sometimes". Within the index learning demands, the question "Does your work require new knowledge and skills" had the highest mean value. The question "Are your work tasks too difficult” had the lowest mean value, meaning that the work fairly seldom was too difficult. Concerning quantitative job demands all questions had a mean below 3.0, so working overtime was not a big problem. Nor did the staff felt that the work piled up or that there was too much to do or that it was necessary to work in a rapid pace.

Job control was studied by positive challenges at work; decision control and work pace control. The individual question with the highest mean value was "Do you consider your work meaningful" with a mean of 4.5 and the question with the lowest mean value was "Can you influence decisions concerning the people you work with" with a mean value of 1.7. Overall the staff had difficulties to influence decisions concerning their own work situation (Table 2).

\subsection{Which Predictors Could Explain Workability and Job Satisfaction?}

Multiple regression analyses were performed with the indexes workability and job satisfaction respectively as

Table 1. The ten question in the dimension "job demands", as well as the indexes "quantitative job demands" (QWD), "learning demands” (LD) and “decision demands” (DD).

\begin{tabular}{|c|c|c|c|c|c|}
\hline Job demands & $\mathrm{N}$ & Min & Max & Mean & sd \\
\hline Is your workload irregular so that the work pile up (QWD) & 63 & 1 & 5 & 2.7 & 1.0 \\
\hline Do you have to work overtime (QWD) & 65 & 1 & 5 & 2.3 & 1.0 \\
\hline Is it necessary to work at a rapid pace (QWD) & 64 & 1 & 4 & 2.8 & 0.9 \\
\hline Do you have too much to do (QWD) & 65 & 1 & 5 & 2.9 & 1.0 \\
\hline Does your work require that you acquire new knowledge and skills (LD) & 64 & 2 & 5 & 3.4 & 0.8 \\
\hline Do you perform work tasks for which you need more training (LD) & 63 & 1 & 5 & 2.7 & 0.9 \\
\hline Are your work tasks too difficult for you (LD) & 65 & 1 & 3 & 1.8 & 0.7 \\
\hline Does your work require maximum attention (DD) & 65 & 2 & 5 & 4.0 & 0.8 \\
\hline Does your work require complex decisions (DD) & 65 & 1 & 5 & 3.1 & 0.9 \\
\hline Does your work require quick decisions (DD) & 64 & 2 & 5 & 3.6 & 0.7 \\
\hline Index quantitative job demands (QWD) 4 questions & 63 & 1 & 5 & 2.7 & 3.0 \\
\hline Index learning demands (LD) 3 questions & 63 & 2 & 5 & 2.6 & 1.7 \\
\hline Index decision demands (DD) 3 questions & 64 & 2 & 5 & 3.6 & 1.8 \\
\hline
\end{tabular}


Table 2. The 12 questions in the dimension job control as well as the indexes "positive challenges at work" (PC) 3 questions, “decision control” (DC) 5 questions and "work pace control” (WPC) 4 questions.

\begin{tabular}{|c|c|c|c|c|c|}
\hline Job control & $\mathbf{N}$ & Min & Max & Mean & sd \\
\hline Are your skills and knowledge useful in your work (PC) & 64 & 1 & 5 & 4.1 & 0.7 \\
\hline Is your work challenging in a positive way (PC) & 65 & 1 & 5 & 3.7 & 0.9 \\
\hline Do you consider your work meaningful (PC) & 65 & 2 & 5 & 4.5 & 0.7 \\
\hline Can you choose alternative methods (DC) & 63 & 1 & 4 & 2.6 & 0.6 \\
\hline Can you influence your amount of work (DC) & 64 & 1 & 5 & 2.6 & 0.9 \\
\hline Can you decide when to be in contact with clients (DC) & 61 & 1 & 5 & 2.1 & 1.2 \\
\hline Can you influence decisions that are important for your work (DC) & 62 & 2 & 5 & 3.3 & 0.7 \\
\hline Can you influence decisions concerning the people you work with (DC) & 64 & 1 & 4 & 1.7 & 0.9 \\
\hline Can you set your own working hours (WPC) & 64 & 1 & 4 & 1.8 & 1.0 \\
\hline Can you set your own workplace (WPC) & 63 & 1 & 3 & 3.0 & 0.8 \\
\hline Can decide when to take a break (WPC) & 64 & 1 & 5 & 2.8 & 1.1 \\
\hline Index positive challenges (PC) & 64 & 1 & 5 & 4.3 & 1.6 \\
\hline Index decision control (DC) & 64 & 1 & 5 & 3.1 & 2.5 \\
\hline Index work pace control (WPC) & 62 & 1 & 5 & 2.7 & 2.8 \\
\hline
\end{tabular}

dependent variables and with individual background variables and all psychosocial indexes as independent variables. In addition, when job satisfaction was the dependent variable, workability was also included in the analysis as it also may influence job satisfaction and when workability was the dependent variable job satisfaction was also included in the analyses as it also may influence workability. The results showed that $46 \%$ of the variance in workability could be explained by positive challenges in work and not being hindered in work by musculoskeletal symptoms. In addition, $70 \%$ of the variance in job satisfaction could be explained by mastery, workability and not having pain during the last 7 days (Table 3 ).

\section{Discussion}

\subsection{How Was the Prevalence of Musculoskeletal Symptoms and Physical Exertion?}

Neck, lumbar and wrist lumbar symptoms were the most frequently described symptoms. Concerning physical exertion, the study group had a perceived exertion with a mean value of 12, indicating a fairly low level of total physical exertion in work according to the Borg's perceived exertion scale [28].

Of all participants in the present study, 59.5\% declared that they were able to work; despite of some discomfort and 5.4\% declared that they had changed their approach to work or reduced their work pace. Previous studies have shown that the main predictor of sickness absence among health care staff is earlier and repeated back problems [31]-[33]. Factors such as the ability to adapt work tasks to one's health situation, work motivation and/or benefits of being present or absent from work may influence work presence [34]. Today, a tendency to be at work and not on sick leave while being sick for musculoskeletal symptoms due to economic and other reasons can be noted in Sweden [35]. Factors like shortage of staff, time pressure and care about colleagues may make people go to work without regard to their own health. This may also be true for employees working with people with cognitive restrictions. They may feel that they are needed and important at the workplace in spite of having symptoms. It is not yet known how this affects the well-being of colleagues, it remains to be studied. It may also be so that in workplaces where it is possible to adapt work tasks and work pace to one's daily capacity, there may be an even higher frequency of employees present at work in spite of various disorders. Ultimately, this could lead to more and longer sick leave periods later on. This is true particularly in health care, where women account for a larger proportion of sickness absence than men and more women also retire earlier than men, due to deteriorating health [36]. 
Table 3. Multiple regression analyses (the stepwise model) on the indexes workability and job satisfaction.

\begin{tabular}{|c|c|c|c|c|}
\hline Workability & Beta coefficient & Increase in $\mathrm{R}$ square & R square & $\mathrm{F}(\mathrm{df})$ \\
\hline Intercept & 3.9 & & & $10.6(2)$ \\
\hline Positive challenges & 0.51 & 0.29 & 0.32 & \\
\hline Not being hindered in work due to musculoskeletal symptoms & 0.44 & 0.17 & 0.51 & \\
\hline \multicolumn{5}{|l|}{ Job satisfaction } \\
\hline Intercept & 1.6 & & & $33.3(3)$ \\
\hline Mastery & 050 & 0.53 & 0.53 & \\
\hline Workability & 0.52 & 0.13 & 0.69 & \\
\hline Pain the last 7 days & -0.19 & 0.04 & 0.73 & \\
\hline
\end{tabular}

\subsection{How Was the Psychosocial Work Situation Perceived?}

The study showed that $80 \%$ of the respondents were satisfied with their current job. The staff also had a good ability to master problems at work, but not so good ability to influence the quality of the work. Decision demands were high compared to quantitative job demands and learning demands at work, but in total they had a positive psychosocial work situation with complex decision-making. Earlier research has shown that high job satisfaction and well-being are characteristics of a healthy work organization [37]. On the other hand, research has also shown that work stress is an important predictor for low job satisfaction [38]. A recent review on the effectiveness of work place health promotion showed that individually tailored programs and a supportive workplace culture were important factors for effective workplace health promotion. It showed that, high stress, poor relations with co-workers and management and lack of exercise were risk factors, not supporting the development of a healthy work place [39]. A study identifying workability promoting factors for nursing assistants found that their self-efficacy, level of perceived personal safety and physical wellbeing were predictors of high workability [40]. For care aides in the same study, safety climate, seniority and age where the main factors contributing to high workability. Knowledge and personal awareness of health promoting factors at work, together with supervisory support in improving the work environment may reduce the frequency of sickness presence and sick-leaves [39]. A focus on increasing the knowledge and awareness of health risks and how to reduce these risks seems to be important for health professionals working with people with cognitive restrictions.

\subsection{Which Predictors Could Explain Workability and Job Satisfaction?}

In the present study, the factors positive challenges in work and not being hindered by MSD's were significant predictors of workability for this group of professionals working with people with cognitive restrictions. In earlier research, health and having a job have been shown to be main predictors of workability [41]. Also the level of physical work demands and safety climate at work may explain workability [40] [42]. The workability has been shown to be reduced and the frequency of MSD's increased when physical work demands exceed workers physical capacities [5]. So, physical as well as psychosocial health may be predictors for workability [43] [44]. Workability is not only the ability to perform a particular work task. Workplace factors, individual factors, physical, psychological, and factors outside the workplace all contribute to workability [4] and have to be considered for an effective workplace health promotion. This may be further researched. It is important that the staff, managers and work place representatives together take responsibility for future efforts to develop a healthy workplace.

\subsection{Limitation}

The low response rate may be explained by the fact that the managers were busy and had difficulties to engage all employees and it took some months to collect the data. However, two reminders were given. It was not possible to use an on-line questionnaire, as not all employees had access to computers at their workplace, which otherwise may have increased the response rate. We analyzed the data on group level, and guaranteed confidential- 
ity in line with the Helsinki declaration and informed consent was obtained from all participants. The methods used are reliable and valid. The QPS Nordic questionnaire has been tested in large relevant professional groups [22]-[24]. We selected the most relevant dimensions from the QPS Nordic questionnaire, based on earlier knowledge of the psychosocial work situation of the studied group.

\section{Conclusion}

Neck, lumbar and wrist symptoms were the most frequently mentioned, indicated by $40 \%$ of the group. A mean value in physical exertion of 12 according to the Borg scale was noted. The majority of the staff working with people with cognitive restrictions were satisfied with their current job and had a high ability to master their work situation. The decision demands at work were high compared to the quantitative job demands and the learning demands. Positive challenges in work and not being hindered by musculoskeletal disorders could predict workability. Mastery, workability and not having pain during the last 7 days predicted job satisfaction. However, due to the relatively small sample the results have to be interpreted with caution.

\section{Acknowledgements}

We thank the Medical Faculty at Lund University for financial support.

\section{Competing Interests}

The authors declare that they have no competing interests.

\section{Authors Contribution}

The authors declare that they both have made substantial intellectual contribution to the study concerning design, data collection, analysis and interpretation of the results. CK participated in data collection, statistical analysis, interpretation of data and drafting of the manuscript. GG participated in design, statistical analysis, interpretation of data and drafting of the manuscript.

\section{References}

[1] World Health Organization (WHO) (2000) Health Promotion: Bridging the Equity Gap. The 5th Global Conference on Health Promotion, Mexico City.

[2] Shain, M. and Kramer, D.M. (2004) Health Promotion in the Workplace: Framing the Concept; Reviewing the Evidence. Occupational and Environmental Medicine, 61, 643-648. http://dx.doi.org/10.1136/oem.2004.013193

[3] Ilmarinen, J. (2009) Work Ability: A Comprehensive Concept for Occupational Health, Research and Prevention. Scandinavian Journal of Work Environment and Health, 35, 1-5. http://dx.doi.org/10.5271/sjweh.1304

[4] Fadyl, J.K., McPherson, K.M., Schluter, P.J. and Turner-Stokes, L. (2010) Factors Contributing to Work-Ability for Injured Workers: Literature Review and Comparison with Available Measures. Disability \& Rehabilitation, 32, 11731183. http://dx.doi.org/10.3109/09638281003653302

[5] Holtermann, A., Jørgensen, M.B., Gram, B., Christensen, J.R., Faber, A., Overgaard, K., Andersen, J.E., Mortensen, O.S., Sjøgaard, G. and Søgaard, K. (2010) Worksite Interventions for Preventing Physical Deterioration among Employees in Job-Groups with High Physical Work Demands: Background, Design and Conceptual Model of Finale. BMC Public Health, 10, 120. http://dx.doi.org/10.1186/1471-2458-10-120

[6] Fiabane, E., Giorgi, I., Sguazzin, C. and Argentero, P. (2013) Work Engagement and Occupational Stress in Nurses and Other Healthcare Workers: The Role of Organisational and Personal Factors. University of Pavia, Pavia.

[7] (2010) Arbetsmiljöverkets officiella statistik/arbetsorsakade besvär. http://www.av.se/dokument/inenglish/oh/The_swedish_work_environment_act.pdf

[8] Chung, Y.C., Hung, C.T., Li, S.-F., Lee, H.-M., Wang, S.-G., Chang, S.-C., Pai, L.-W., Huang, C.-N. and Yang, J.-H. (2013) Risk of Musculoskeletal Disorder among Taiwanese Nurses Cohort: A Nationwide Population-Based Study. BMC Musculoskeletal Disorders, 14, 144. http://dx.doi.org/10.1186/1471-2474-14-144

[9] (2013) The Work Environment Act. Theme: High Physical Strain within Health Care. http://www.av.se/dokument/statistik/officiell_stat/

[10] European Agency for Health at Work (2012) Work-Related Musculoskeletal Disorders at Work. Facts and Figures. https:/osha.europa.eu//en/publications/reports/TERO09009ENC 
[11] Hämming, O., Knecht, M., Läubli, T. and Bauer, G.F. (2011) Work-Life Conflict and Musculoskeletal Disorders: A Cross-Sectional Study of an Unexplored Association. BMC Musculoskeletal Disorders, 12, 60. http://www.biomedcentral.com/1471-2474/12/60

[12] Hauke, A., Flintrop, J., Brun, E. and Rugulie, R. (2011) The Impact of Work-Related Psychosocial Stressors on the Onset of Musculoskeletal Disorders in Specific Body Regions: A Review and Meta-Analysis of 54 Longitudinal Studies. Work \& Stress, 25, 243-256. http://dx.doi.org/10.1080/02678373.2011.614069

[13] Torp, S., Riise, T. and Moen, B.E. (2001) The Impact of Psychosocial Work Factors on Musculoskeletal Pain: A Prospective Study. Journal of Occupational and Environmental Medicine, 43, 120-126. http://dx.doi.org/10.1097/00043764-200102000-00010

[14] Leijon, O., Härenstam, A., Waldenström, K., Alderling, M. and Vingård, E. (2006) Target Groups for Prevention of Neck/Shoulder and Low Back Disorders: An Exploratory Cluster Analysis of Working and Living Conditions. Work, 27, 189-204.

[15] Driessen, M.T., Proper, K.I., van Tulder, M.W., Anema, J.R., Bongers, P.M. and van der Beek, A.J. (2010) The Effectiveness of Physical and Organisational Ergonomic Interventions on Low Back Pain and Neck Pain: A Systematic Review. Occupational and Environmental Medicine, 67, 277-285. http://dx.doi.org/10.1136/oem.2009.047548

[16] Proper, K.I., de Bruyne, M.C., Hildebrandt, V.H., van der Beek, A.J., Meerding, W.J. and Van Mechelen, W. (2004) Costs, Benefits and Effectiveness of Worksite Physical Activity Counseling from the Employer's Perspective. Scandinavian Journal of Work, Environment \& Health, 30, 36-46. http://dx.doi.org/10.5271/sjweh.763

[17] Lindvall, U. (2010) Long-Term Sickness Absence. Aspects of Society, Work and Family. Department of Neuroscience, Division of Insurance Medicine, The Karolinska Institute, Stockholm.

[18] Gray-Stanley, J.A., Muramatsu, N., Heller, T., Hughes, S., Johnson, T.P. and Ramirez-Valles, J. (2010) Work Stress and Depression among Direct Support Professionals: The Role of Work Support and Locus of Control. Journal of Intellectual Disability Research, 54, 749-761. http://dx.doi.org/10.1111/j.1365-2788.2010.01303.x

[19] Innstrand, S.T., Espnes, G.A. and Mykletun, R. (2002) Burnout among People Working with Intellectual Disabled Persons: A Theory Update and an Example. Scandinavian Journal of Caring Sciences, 16, 272-279. http://dx.doi.org/10.1046/j.1471-6712.2002.00084.x

[20] Kowalski, C., Driller, E., Ernstmann, N., Alich, S., Karbach, U., Ommen, O., Schulz-Nieswandt, F. and Pfaff, H. (2010) Associations between Emotional Exhaustion, Socialcapital, Workload and Latitude in Decision-Making among Professionals Working with People with Disabilities. Research in Developmental Disabilities, 31, 470-479. http://dx.doi.org/10.1016/j.ridd.2009.10.021

[21] Faragher, E.B., Cass, M. and Cooper, C.L. (2005) The Relationship between Job Satisfaction and Health: A MetaAnalysis. Occupational and Environmental Medicine, 62, 105-112. http://dx.doi.org/10.1136/oem.2002.006734

[22] Lindström, K., Elo, A.L., et al. (2000) User’s Guide for the QPS Nordic. General Nordic Questionnaire for Psychological and Social Factors at Work. Copenhagen.

[23] Lindström, K., Dallner, M., Elo, A.L., Gamberale, F., Knardahl, S., Skogstad, A. and Örhede, E. (1997) QPS Nordic. Nordic Councils of Ministers, Helsinki.

[24] Dallner, M., Elo, A.L., Gamberlále, F., Hottinen, V., Knardahl, S., Lindström, K. and Örhede, E.S. (2000) Validation of the General Nordic Questionnaire QPS Nordic for Psychological and Social Factors at Work. Nordic Council of Ministers, Copenhagen.

[25] Kourinka, I., Johnsson, B., Kilbom, A., Vinterberg, H., Biering-Sørensen, F., Andersson, G., et al. (1987) Standardised Nordic Questionnaire for the Analysis of Musculoskletal Symptoms. Applied Ergonomics, 18, 233-237. http://dx.doi.org/10.1016/0003-6870(87)90010-X

[26] Toumi, K., Illmarinen, J., Jahkola, A., Katajarinne, L. and Tulkki, A. (1998) WAI: A Method for Work Ability Assessment. Swedish Version Helsinki, Finland National Institute for Working Life.

[27] Ilmarinen, J. (2007) Work Ability Index (WAI). Occupational Medicine, 57, 16.

[28] Borg, G. (1970) Perceived Exertion as an Indicator of Somatic Stress. Scandinavian Journal of Rehabilitation Medicine, 2, 92-98.

[29] Scott, J. and Husisson, E.C. (1976) Graphic Representation of Pain. Pain, 2, 175-184. http://dx.doi.org/10.1016/0304-3959(76)90113-5

[30] Hair, J.F., Anderson, R.E., Tatham, R. and Black, W. (1998) Multivariate Data Analysis. Prentice Hall, Upper Saddle River.

[31] Smedley, J., Egger, P., Cooper, C. and Coggon, D. (1997) Prospective Cohort Study of Predictors of Incident Low Back Pain in Nurses. BMJ, 314, 1225-1228. http://dx.doi.org/10.1136/bmj.314.7089.1225

[32] Lagerström, M., Hansson, T. and Hagberg, M. (1998) Work-Related Low-Back Problems in Nursing. Scandinavian 
Journal of Work, Environment \& Health, 24, 449-464. http://dx.doi.org/10.5271/sjweh.369

[33] Horneij, E.L, Jensen, I.B., Holmström, E.B. and Ekdahl, C. (2004) Sick Leave among Home-Care Personnel: A Longitudinal Study of Risk Factors. BMC Musculoskeletal Disorders, 5, 38. http://dx.doi.org/10.1186/1471-2474-5-38

[34] Johansson, G. (2007) The Illness Flexibility Model and Sickness Absence. The Karolinska Institute, Stockholm.

[35] Swedish Council on Health Technology Assessment, SBU (2012) Work Relevance of the Onset of Symptoms and Diseases. Neck and Upper Musculoskeletal System. Asystematic Literature Review. SBU Report.

[36] (2012) Women's Work Environment. The Work Agency. http://www.av.se/dokument/omoss/regeringsuppdrag/2012_03_13_kvinnors_arbetsmiljo.pdf

[37] Svensson-Dahlgren, A. and Gard, G. (2009) Soft Values with Hard Impact. A Review of Stress Reducing Interventions on Group and Organisational Level. Physical Therapy Reviews, 14, 369-381.

[38] Ge, C., Fu, J., Chang, Y. and Wang, L. (2011) Factors Associated with Job Satisfaction among Chinese Community Health Workers: A Cross-Sectional Study. BMC Public Health, 11, 884. http://dx.doi.org/10.1186/1471-2458-11-884

[39] Cancelliere, C., Cassidy, J.D., Ammendolia, C. and Côté, P. (2011) Are Workplace Health Promotion Programs Effective at Improving Presenteeism in Workers? A Systematic Review and Best Evidence Synthesis of the Literature. BMC Public Health, 11, 395. http://dx.doi.org/10.1186/1471-2458-11-395

[40] Larsson, A., Karlqvist, L., Westerberg, M. and Gard, G. (2012) Identifying Work Ability Promoting Factors for Home Care Aides and Assistant Nurses. BMC Musculoskeletal Disorders, 13, 1.

[41] Joling, C., Blatter, B.M., Ybema, J.F. and Bongers, P.M. (2008) Can Favorable Psychosocial Work Conditions and High Work Dedication Protect against the Occurrence of Work-Related Musculoskeletal Disorders? Scandinavian Journal of Work, Environment \& Health, 34, 345-355. http://dx.doi.org/10.5271/sjweh.1274

[42] Thorsen, S.V., Burr, H., Diderichsen, F. and Bjorner, J.B. (2012) A One-Item Workability Measure Mediates Work Demands, Individual Resources and Health in the Prediction of Sickness Absence. National Research Centre for the Working Environment, Copenhagen.

[43] Gould, R., Ilmarinen, J., Järvisalo, J. and Koskinen, S. (2008) Dimensions of Work Ability. Results of the Health 2000 Survey. Helsinki, Finnish Centre for Pensions, The Social Insurance Institution, National Public Health Institute, Finnish Institute of Occupational Health.

[44] Holmgren, K., Dahlin-Ivanoff, S., Björkelund, C. and Hensing, G. (2009) The Prevalence of Work Related Stress, and Its Association with Self-Perceived Health and Sick-Leave, in a Population of Employed Swedish Women. BMC Public Health, 9, 73-73. 
Scientific Research Publishing (SCIRP) is one of the largest Open Access journal publishers. It is currently publishing more than 200 open access, online, peer-reviewed journals covering a wide range of academic disciplines. SCIRP serves the worldwide academic communities and contributes to the progress and application of science with its publication.

Other selected journals from SCIRP are listed as below. Submit your manuscript to us via either submit@scirp.org or Online Submission Portal.
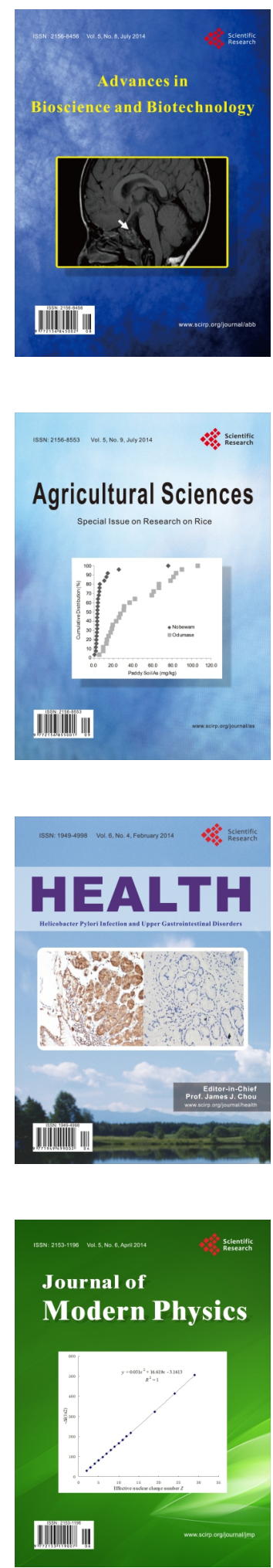
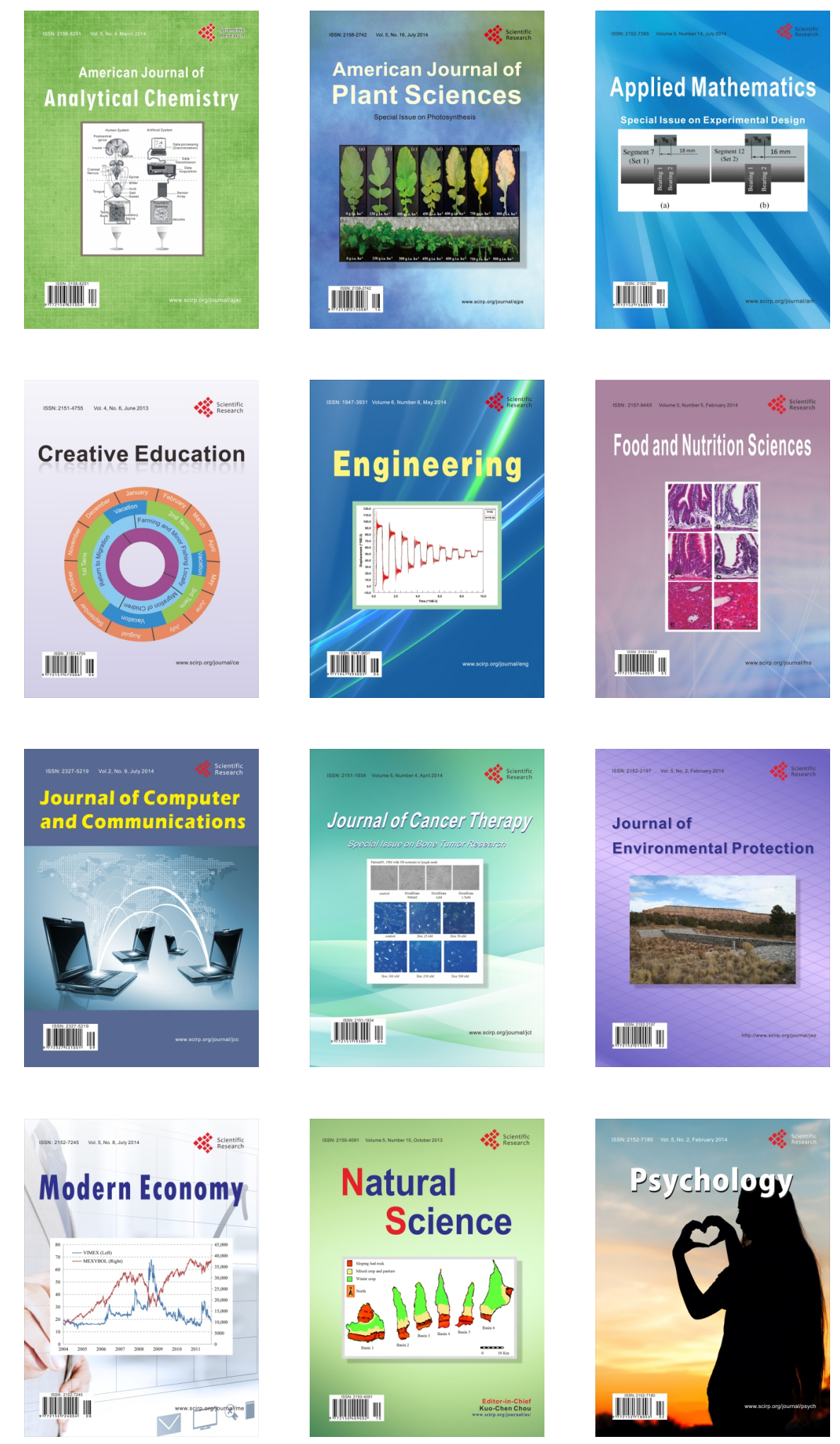